NASA/TM-2012-217698

\title{
Flight Simulator Evaluation of Enhanced Propulsion Control Modes for Emergency Operation
}

Jonathan S. Litt

Glenn Research Center, Cleveland, Ohio

T. Shane Sowers

Vantage Partners, LLC, Brook Park, Ohio

A. Karl Owen

Motile Robotics, Inc., Joppa, Maryland

Christopher E. Fulton

Zin Technologies, Middleburg Heights, Ohio

Amy K. Chicatelli

Vantage Partners, LLC, Brook Park, Ohio 


\section{NASA STI Program . . . in Profile}

Since its founding, NASA has been dedicated to the advancement of aeronautics and space science. The NASA Scientific and Technical Information (STI) program plays a key part in helping NASA maintain this important role.

The NASA STI Program operates under the auspices of the Agency Chief Information Officer. It collects, organizes, provides for archiving, and disseminates NASA's STI. The NASA STI program provides access to the NASA Aeronautics and Space Database and its public interface, the NASA Technical Reports Server, thus providing one of the largest collections of aeronautical and space science STI in the world. Results are published in both non-NASA channels and by NASA in the NASA STI Report Series, which includes the following report types:

- TECHNICAL PUBLICATION. Reports of completed research or a major significant phase of research that present the results of NASA programs and include extensive data or theoretical analysis. Includes compilations of significant scientific and technical data and information deemed to be of continuing reference value. NASA counterpart of peer-reviewed formal professional papers but has less stringent limitations on manuscript length and extent of graphic presentations.

- TECHNICAL MEMORANDUM. Scientific and technical findings that are preliminary or of specialized interest, e.g., quick release reports, working papers, and bibliographies that contain minimal annotation. Does not contain extensive analysis.

- CONTRACTOR REPORT. Scientific and technical findings by NASA-sponsored contractors and grantees.
- CONFERENCE PUBLICATION. Collected papers from scientific and technical conferences, symposia, seminars, or other meetings sponsored or cosponsored by NASA.

- SPECIAL PUBLICATION. Scientific, technical, or historical information from NASA programs, projects, and missions, often concerned with subjects having substantial public interest.

- TECHNICAL TRANSLATION. Englishlanguage translations of foreign scientific and technical material pertinent to NASA's mission.

Specialized services also include creating custom thesauri, building customized databases, organizing and publishing research results.

For more information about the NASA STI program, see the following:

- Access the NASA STI program home page at http://www.sti.nasa.gov

- E-mail your question to help@sti.nasa.gov

- Fax your question to the NASA STI Information Desk at 443-757-5803

- Phone the NASA STI Information Desk at 443-757-5802

- Write to: STI Information Desk NASA Center for AeroSpace Information 7115 Standard Drive Hanover, MD 21076-1320 
NASA/TM-2012-217698

AIAA-2012-2604

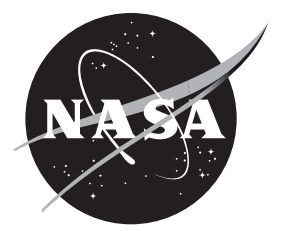

\section{Flight Simulator Evaluation of Enhanced Propulsion Control Modes for Emergency Operation}

Jonathan S. Litt

Glenn Research Center, Cleveland, Ohio

T. Shane Sowers

Vantage Partners, LLC, Brook Park, Ohio

A. Karl Owen

Motile Robotics, Inc., Joppa, Maryland

Christopher E. Fulton

Zin Technologies, Middleburg Heights, Ohio

Amy K. Chicatelli

Vantage Partners, LLC, Brook Park, Ohio

Prepared for the

Infotech@Aerospace 2012 Conference

sponsored by the American Institute of Aeronautics and Astronautics

Garden Grove, California, June 19-21, 2012

National Aeronautics and

Space Administration

Glenn Research Center

Cleveland, Ohio 44135 


\section{Acknowledgments}

The authors thank Ten-Huei Guo and Ryan D. May for guidance in the implementation and testing of the yaw rate feedback. The authors acknowledge the NASA Aviation Safety Program's Vehicle Systems Safety Technologies Project for funding this work.

Level of Review: This material has been technically reviewed by technical management.

Available from

NASA Center for Aerospace Information 7115 Standard Drive

Hanover, MD 21076-1320
National Technical Information Service 5301 Shawnee Road Alexandria, VA 22312

Available electronically at http://www.sti.nasa.gov 


\title{
Flight Simulator Evaluation of Enhanced Propulsion Control Modes for Emergency Operation
}

\author{
Jonathan S. Litt \\ National Aeronautics and Space Administration \\ Glenn Research Center \\ Cleveland, Ohio 44135 \\ T. Shane Sowers \\ Vantage Partners, LLC \\ Brook Park, Ohio 44142 \\ A. Karl Owen \\ Motile Robotics, Inc. \\ Joppa, Maryland 21085 \\ Christopher E. Fulton \\ Zin Technologies \\ Middleburg Heights, Ohio 44130 \\ Amy K. Chicatelli \\ Vantage Partners, LLC \\ Brook Park, Ohio 44142
}

\begin{abstract}
This paper describes piloted evaluation of enhanced propulsion control modes for emergency operation of aircraft. Fast Response and Overthrust modes were implemented to assess their ability to help avoid or mitigate potentially catastrophic situations, both on the ground and in flight. Tests were conducted to determine the reduction in takeoff distance achievable using the Overthrust mode. Also, improvements in Dutch roll damping, enabled by using yaw rate feedback to the engines to replace the function of a stuck rudder, were investigated. Finally, pilot workload and ability to handle the impaired aircraft on approach and landing were studied. The results showed that improvement in all aspects is possible with these enhanced propulsion control modes, but the way in which they are initiated and incorporated is important for pilot comfort and perceived benefit.
\end{abstract}

\section{Introduction}

Previous in-flight emergencies in which flight control has been partially or totally lost, have required pilots to learn how to fly the damaged aircraft, sometimes requiring innovative approaches. The use of differential thrust for maneuvering is an example that has been used successfully on several occasions (Refs. 1 to 4). Other examples of mid-air or on-the-ground crises, such as accidents caused by runway incursions or attempted take-offs from the wrong runway, have not ended well (Refs. 5 to 7). However, it has been speculated that in some cases there is a potential safety improvement possible through the incorporation of additional propulsion system capability (Ref. 8).

The engines are the most powerful actuators on the aircraft, and have a large role to play in upset recovery and accident prevention. For instance, it is possible to use differential thrust to replace or augment the function of a damaged rudder and vertical tail. However, when using the engines alone for maneuvering, an aircraft can take as much as 5 to 10 times as long to respond compared to using the conventional flight control surfaces (Ref. 9). This lag in response is due to the relatively slower engine 
dynamics; additionally, engine placement dictates the control authority the engines have on the aircraft. Besides the ability to maneuver and land a disabled aircraft, as demonstrated in the UAL 232 Sioux City accident (Ref. 1) and the DHL A300-B4 Baghdad event (Ref. 4), there are other more subtle capabilities of the flight control system that can be assumed by the propulsion system in case of an emergency, such as maintaining acceptable handling qualities (or at least aircraft stability). For instance, Dutch roll is a combined roll and yaw oscillation that is normally very lightly damped in swept-wing aircraft such as modern airliners. To increase the damping of the Dutch roll oscillations, a yaw damper is installed that measures the yaw rate of the aircraft and makes necessary commands to the rudder to compensate. In the event of vertical tail damage, the aircraft's natural tendency to damp the Dutch roll oscillations is reduced, and with no rudder, the yaw damper will become ineffective. Previous NASA research aimed at using the throttles alone to maneuver an aircraft with no flight control system specifically identified sluggish engine response and Dutch roll as problems (Ref. 10). As a result of these findings, follow-on research to develop a propulsion-based automatic flight control system known as Propulsion Controlled Aircraft (PCA) was pursued (Ref. 11). This system proved successful in both alleviating much of the lightly damped aircraft behavior, and in reducing pilot workload.

Another safety-enhancing feature that that has not been previously studied is the ability of the propulsion system to provide additional thrust beyond the normal maximum. This capability could be used to shorten the required take-off distance, for instance, in the case of an aircraft that mistakenly utilizes a runway that is too short.

Research into achieving enhanced engine responsiveness to address these situations has revealed that the potential exists to greatly improve engine performance through control system modifications alone (Ref. 12) albeit with a slightly increased risk to the engine (Ref. 13). This risk is mitigated, however, by the overall safety improvement to the distressed vehicle (Ref. 8). In preparation to investigate the improvement in controllability and thus safety for the imperiled aircraft, enhanced propulsion control modes for emergency flight operation have been developed and demonstrated in simulation (Refs. 13 to 15). Specifically, the two modes are Overthrust and Fast Response, which relate to emergency situations such as runway incursion and loss of flight control effectiveness, respectively.

This paper describes on-going flight simulator evaluation of enhanced propulsion control modes as the pilot attempts to complete various tasks with an impaired aircraft, specifically with the rudder stuck in the neutral position. The intent is to begin to characterize the limitations of using the standard propulsion control available with the nominal or impaired aircraft, and the improvement achievable using the enhanced propulsion control modes. The performance improvements enabled by these modes have the potential to provide safety enhancements over using the nominal engines, whether for throttles-only maneuvering or as part of a specially designed flight control system such as PCA. The enhanced propulsion control modes are described in the next section. The remainder of the paper describes the results of several tests used to evaluate the effectiveness of the enhanced propulsion control modes, and their integration into the aircraft for ease of use. Based on these results, conclusions are drawn.

\section{Simulator and Enhancements}

The enhanced propulsion control modes were implemented for the engines (Ref. 12) of a nonlinear simulation of a four-engine transport aircraft. The engine performance is representative of actual engines in their thrust class (Ref. 16), and the enhanced control modes are realistically achievable. This simulation was incorporated into a fixed-base flight simulator that was developed to evaluate the impact of propulsion control innovations on flight operation. The cockpit (Figure 1) has two throttles which are used for the left and right side engines, meaning that the inboard and outboard engines on each side are always at the same power setting. The pilot has switches in the cockpit to turn the Overthrust and Fast Response modes on and off individually. The pilot can set the flaps and landing gear. The cockpit also has rudder pedals and a stick. There are no other controls. No wind was included in these tests. 


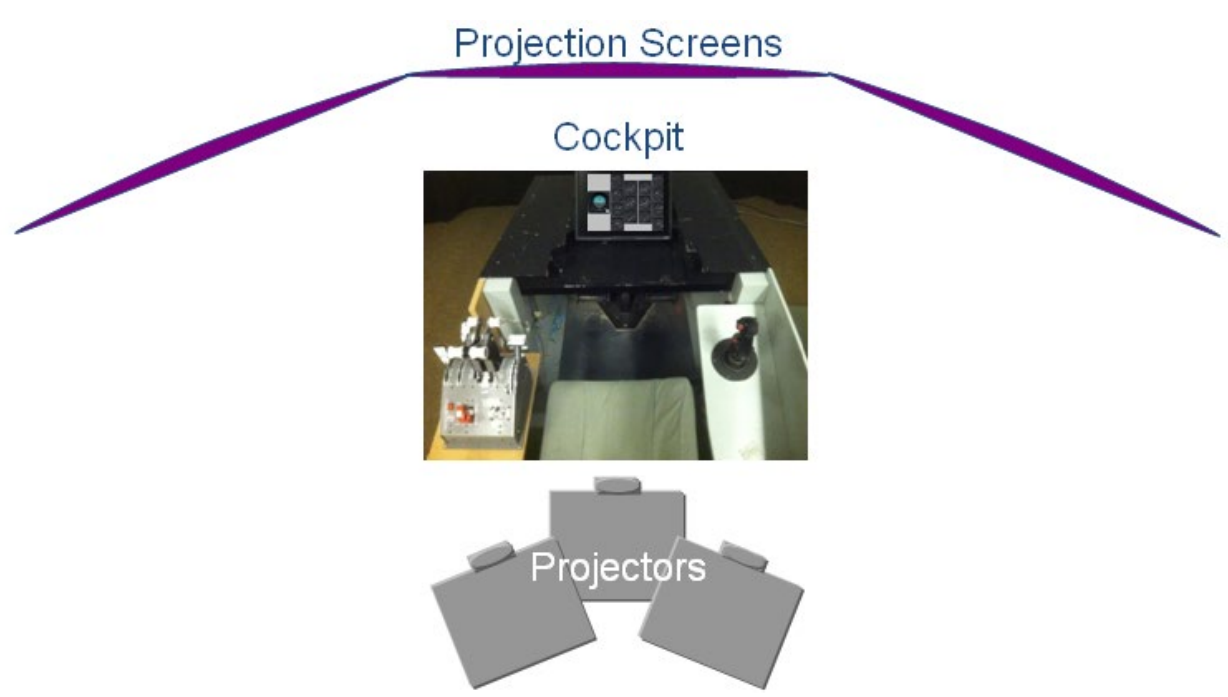

Figure 1.-Flight simulator setup.

\section{Overthrust}

The impact of the Overthrust control mode is shown in Figure 2. The throttle position, which corresponds to the thrust setpoint, is moved higher than the normal 100 percent, and control limits that might otherwise be hit are relaxed to enable the engine to produce thrust beyond its normal maximum. In the figure, the initial power level corresponds to 100 percent thrust. At $10 \mathrm{~s}$, Overthrust mode is initiated, resulting in the various overlaid transients up to higher thrust levels. Here each higher thrust level corresponds to a different level of risk of engine failure as the engine is pushed harder and harder.

\section{Fast Response}

The impact of the Fast Response control mode is shown in Figure 3. In this case, the engine is more responsive to large throttle changes because the limits that restrict acceleration have been adjusted to allow faster command following. The thrust response of an engine is typically restricted to accommodate the worst case stack-up of detrimental effects (inlet distortion, engine deterioration, engine-to-engine variation, Reynolds number effects, etc.) to avoid stall and surge (Ref. 9). If one is willing to accept higher risk of surge, or knows with certainty that the worst case situation does not exist, the engine can be allowed to accelerate more rapidly.

\section{Yaw Rate Feedback}

For some of the testing, a yaw rate feedback controller was implemented to aid or potentially replace the rudder function automatically, as opposed to manual manipulation of the throttles (Refs. 15 and 17). The approach taken was similar to that in Reference 15: Multiply the measured yaw rate signal by a gain $\mathrm{k}$ after it passes through a washout filter, and sum the result with the pilot's pedal inputs. This signal is subsequently applied to the throttle settings differentially, as shown in Figure 4. (Note that the throttle setting is sometimes called Power Lever Angle or PLA.) This setup allows the pilot to maintain control over yaw rate using the pedals, and commands zero yaw rate when they are not depressed, which corresponds to a coordinated turn. As can be seen in Figure 4, the yaw rate error is applied to the engines on each side with equal but opposite magnitudes. On one side the throttle is increased, on the other it is decreased by the same amount. This maintains approximately the same total thrust, but applies a yawing moment to the aircraft, which can be used to help maneuver, or to oppose an undesired yaw rate disturbance. 


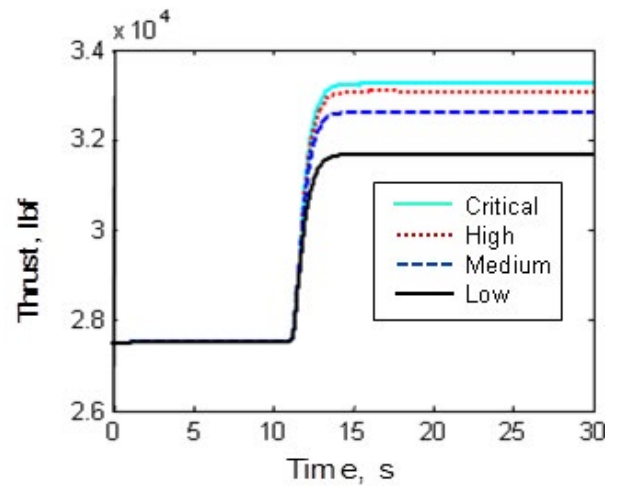

Figure 2.-Examples of Overthrust operation. Thrust levels reach various values above the normal maximum level as the setpoint is raised above 100 percent. The higher the thrust, the greater the risk of engine failure.

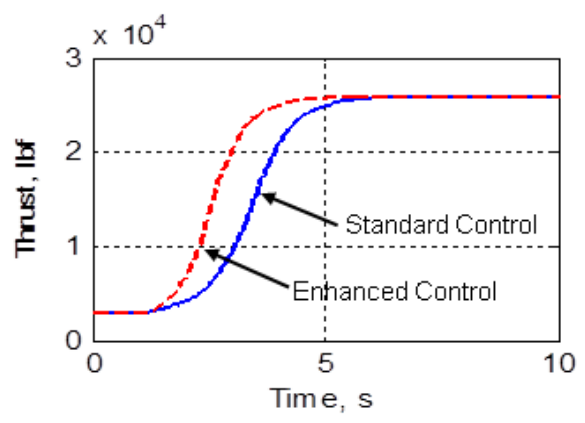

Figure 3.-Fast Response transient showing the ability of the engine to accelerate more rapidly than normal when controller limits are relaxed.

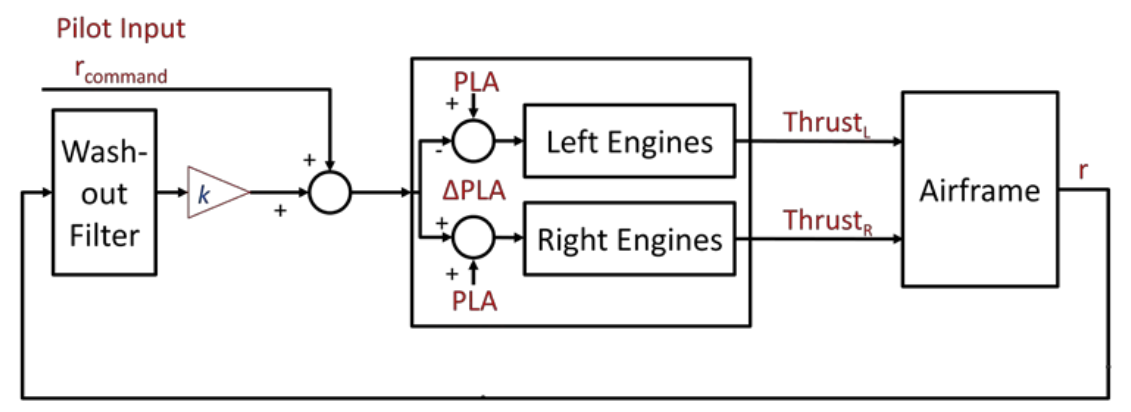

Figure 4.-Yaw rate feedback to differential throttle, where $r$ is yaw rate and PLA is Power Lever Angle or throttle position.

\section{Results}

Three types of tests were conducted. The purpose of the first type was to evaluate the reduction in required takeoff distance obtained using Overthrust for a runway incursion scenario. The second type of testing involved turning with the rudder locked, using nominal and enhanced engine responses, with and without yaw rate feedback. The purpose of these tests was to evaluate Dutch roll damping and the ability to achieve a desired heading. Finally, the third type of testing assessed approach and landing attempts with a disabled rudder, again using a variety of control techniques.

\section{Runway Incursion}

For consistency during these tests, and to eliminate pilot anticipation, runway incursions were not simulated. Since runway incursions are relatively rare events, the pilot would not generally be expecting another aircraft to cross its path during takeoff. However, since the pilot knew it would happen here, even if the tests were randomized, it was decided to eliminate the human factor as much as possible and just begin the takeoff roll with Overthrust mode active. Thus from engine spool-up, the highest throttle setting corresponded to higher than normal takeoff thrust. It is intuitively clear that the required takeoff distance will be shorter with additional thrust, so the focus was on testing the improvement achievable through the use of this emergency control mode, and learning how to ascend in the shortest distance. In this scenario, three types of propulsion control were applied from the start of each respective run: Standard (not enhanced), Overthrust, and a combination of Fast Response and Overthrust. Piloted evaluation showed a clear improvement with Overthrust versus standard control, while the addition of Fast Response made no significant difference, which is to be expected since the fast response reduces the engine spool up time by 


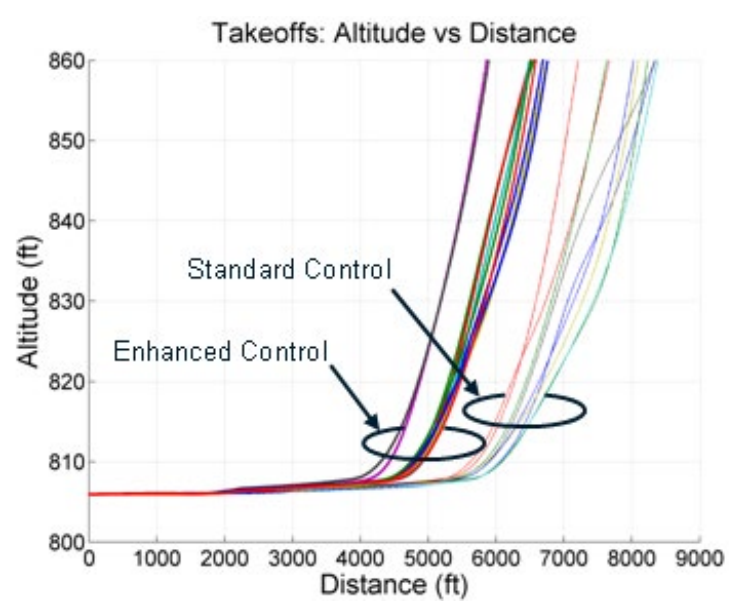

Figure 5.-Comparison of takeoff trajectories with standard control and enhanced control (Overthrust mode enabled).

about $1 \mathrm{~s}$ (Ref. 13) over the approximately $40 \mathrm{~s}$ takeoff roll. Figure 5 shows a comparison of the results for standard control and enhanced control in terms of altitude vs. distance. While there is variation within each group of takeoffs, they are distinct groups with the required takeoff distance shorter by about $1000 \mathrm{ft}$ for the set that used enhanced control.

In an emergency situation, the pilot would have to determine the feasibility of using this control mode. If the plane has already reached takeoff decision speed $\left(\mathrm{V}_{1}\right.$ speed) and cannot stop before impact, its use would be appropriate. In that case, however, the enhanced control mode would be initiated well into the takeoff roll and the distance advantage it provides would be less than seen in this study. On the other hand, under those circumstances, Fast Response might show more of a benefit than it did here.

\section{Turns}

Turns were used to evaluate the stability and controllability improvements made possible through the use of enhanced propulsion control. Two types of test were performed, one to assess Dutch roll damping, and the other to determine the pilot's ability to achieve a desired heading.

\section{Turns Using Stick-Dutch Roll Damping}

The objective of this test was to evaluate the aircraft's ability to damp Dutch roll without pilot intervention. For each trial, the pilot initiated the Dutch roll using the following procedure. He trimmed the aircraft at the desired altitude and speed, moved the stick hard over to the right and banked to $40^{\circ}$, turned right maintaining the roll angle, then rolled out at a desired heading by moving the stick hard over to the left, and then releasing with wings near level, thus causing the Dutch roll. There was some variation from trial to trial, but the starting point after Dutch roll initiation was similar in all cases. The cases included:

- Nominal aircraft, no damage

- Rudder stuck in neutral position with no compensation

- Rudder stuck in neutral position with yaw rate feedback and nominal engines

- Rudder stuck in neutral position with yaw rate feedback and fast-responding engines

Some results are shown in Figure 6 and Figure 7. The trials performed at $5000 \mathrm{ft}, 200 \mathrm{kn}$ (Figure 6), show that using yaw rate feedback provides a significant improvement in damping over the stuck rudder case with no yaw rate feedback, although none are as damped as the nominal case. There is no noticeable difference in the ability to damp between the fast-responding and nominal engines using yaw rate feedback, indicating that the nominal engines are fast enough. However, at 20,000 ft, $300 \mathrm{kn}$ (Figure 7), while the extremes are the same, the fast-responding engines demonstrate a significant improvement in damping over the nominal engines when yaw rate feedback is used. This reveals that the nominal engines are not fast enough to damp the Dutch roll oscillations effectively in this case. 


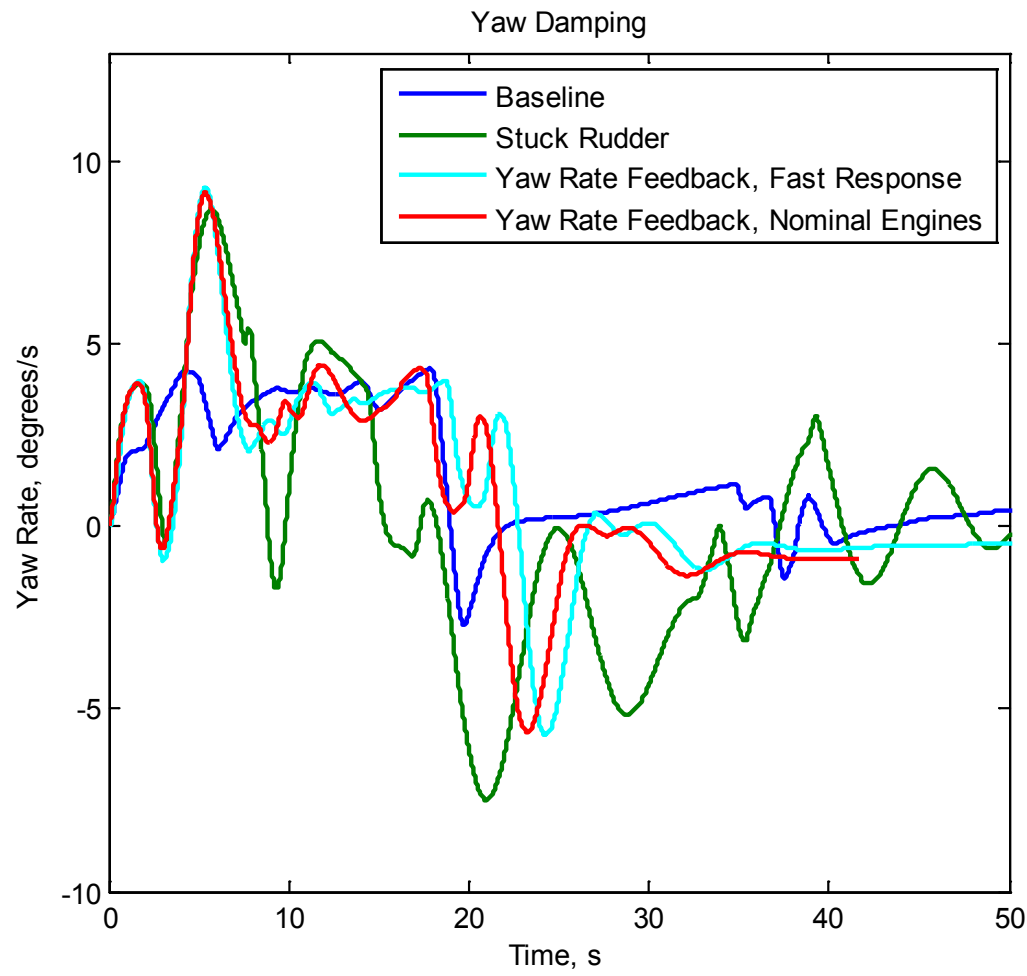

Figure 6.-Yaw rate at $5000 \mathrm{ft}, 200 \mathrm{kn}$ demonstrating similar yaw damping with nominal and faster engine. The pilot initiated a Dutch roll by using the stick to bank and turn, then roll out rapidly.

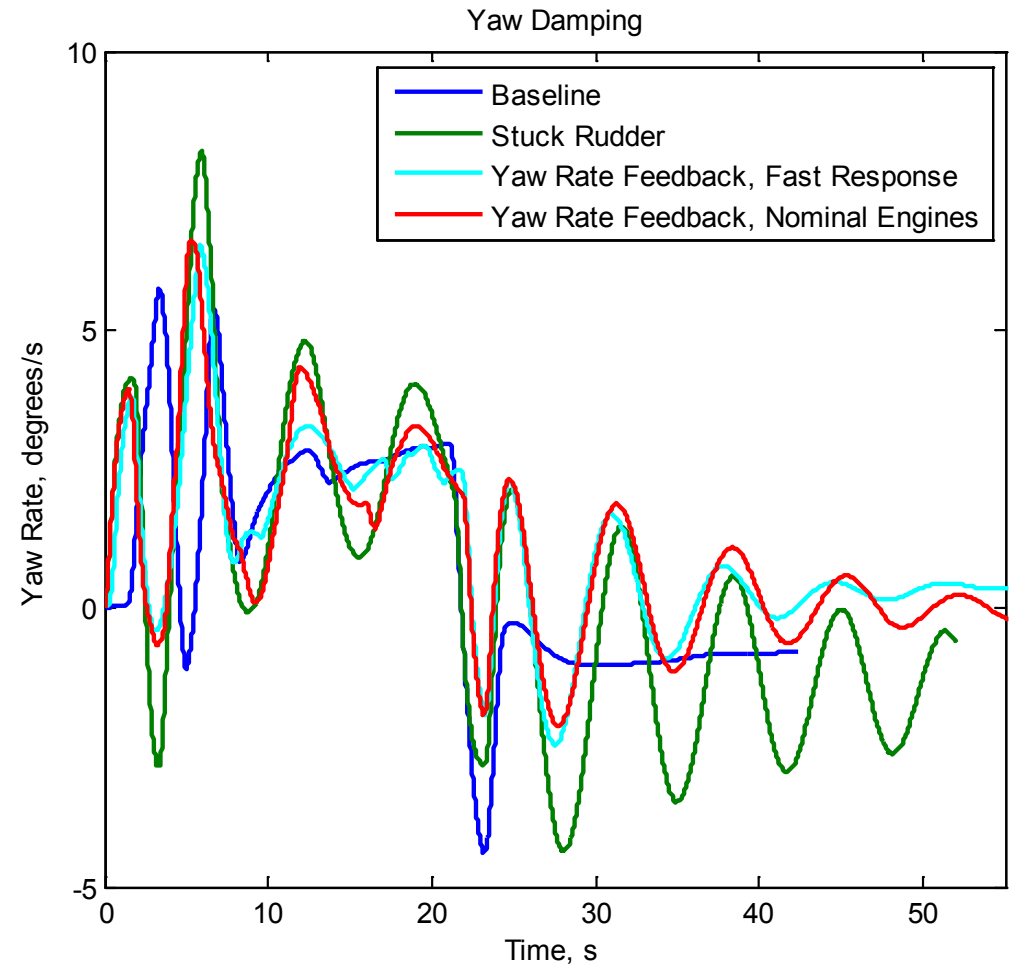

Figure 7.-Yaw rate at 20,000 ft, $300 \mathrm{kn}$ demonstrating improved yaw damping with faster engine. The pilot initiated a Dutch roll by using the stick to bank and turn, then roll out rapidly. 


\section{Turns Using Rudder Pedals}

The purpose of this test was to evaluate the controllability of the aircraft by testing the ability to maintain a desired heading when rolling out of a turn. For this test, the pilot used the stick together with the pedals, when the yaw rate feedback to the throttles was engaged, to bank and turn, then roll out at the desired heading. Figure 8 shows the results in heading and roll angle for the four cases. As usual, the nominal aircraft was very controllable and smooth, and the aircraft with the disabled rudder was much more oscillatory. When using yaw rate feedback to the throttles, the behavior is a little more oscillatory than for the nominal aircraft, regardless of engine response speed, particularly in roll, but is very controllable. The hunting at the end of the run for the final heading is mostly due to the pilot having to anticipate when to apply rudder to stop the turn; the faster engine stopped it too soon, while the nominal engine stopped it too late.

Using the pedals seemed more successful in controlling heading than the use of yaw rate feedback without the pedals. This is likely due to the size of the command that the pilot was able to give with the pedals, and the speed with which he could modulate it, as well as his ability to anticipate. Although the pilot seemed to have good control during this maneuver when yaw rate feedback was engaged, he said that he was not comfortable using the rudder pedals in that way. He said that using the stick without the rudder pedals felt more natural, while using yaw rate feedback did not feel right dynamically. The pilot is used to nearly instantaneous response from the rudder, and although the engine response can be sped up, the inherent delay cannot be avoided altogether. He did not use rudder pedals for any other tests.

\section{Landing}

Several methods of testing landing were evaluated with the stuck rudder; the landing gear started in the lowered position in all cases. The pilot flew using the standard controls with compensation for the stuck rudder, and he used a throttles-only technique. All testing began from a trimmed condition. Locking the rudder in flight in such a case did not cause an upset and was transparent to the pilot.

\section{Landing Using Stick}

In this scenario, the crippled aircraft started out in stabilized flight pointed in the general direction of but offset laterally from the airport. The objective was to maneuver to the airport (Figure 9) and land (Figure 10).
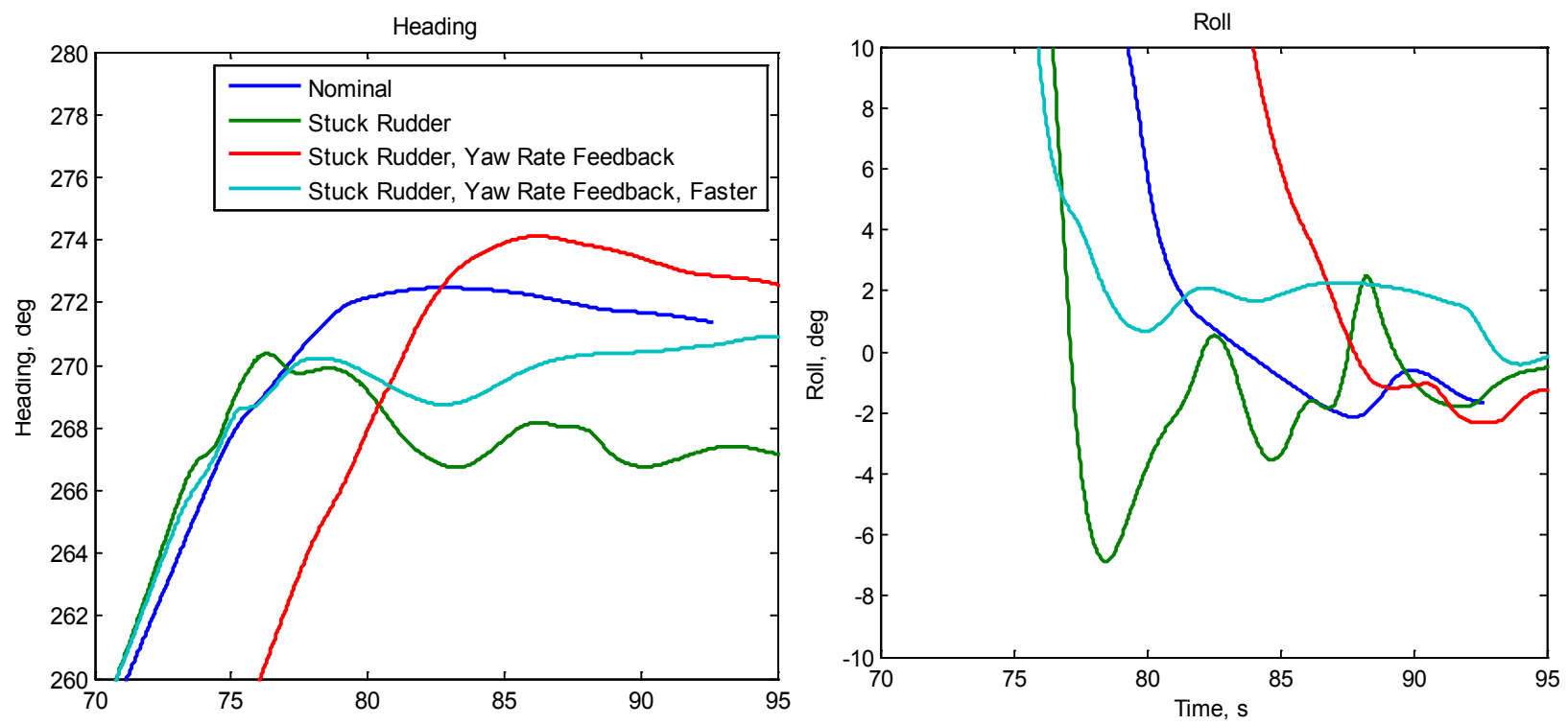

Figure 8.- Roll out at a heading of $270^{\circ}$ after a bank and turn accomplished using rudder pedals and stick. These tests were performed at about $3000 \mathrm{ft}, 250 \mathrm{kn}$. 
The pilot flew using the stick; he did not attempt to use the rudder pedals. The flaps were set at 50 percent. The tests included:

- Rudder stuck in neutral position with no compensation

- Rudder stuck in neutral position with yaw rate feedback and nominal engines

- Rudder stuck in neutral position with yaw rate feedback and fast-responding engines

These were blind randomized tests, during which the pilot did not know the type of engine response or feedback in use. He was very cautious about making or unwilling to make last minute corrections; he flew very conservatively. His comments after each flight indicated that he felt most comfortable without yaw rate feedback because he could better anticipate how the aircraft would react. He seemed to feel least comfortable with yaw rate feedback and fast response. These impressions are particularly interesting because in the best no-yaw-rate feedback case, when he was able to avoid initiating any significant oscillation, the results were no less oscillatory than the cases with yaw rate feedback and faster engines, and generally the compensation reduced oscillation significantly. Additionally, yaw rate feedback with faster engine response always provided the most damping and the smallest oscillations, while nominal engines with yaw rate feedback were often the least damped after the second turn. Figure 11 and Figure 12 show typical results for roll rate and yaw rate. What is clear is that after the first large turn, in the cases with yaw rate feedback the oscillations damp out much more quickly than without. After the second large turn, however, damping for the cases with yaw rate feedback with nominal engines was often worse than for the other cases. In all cases without significant oscillation, on final approach there is a persistent small Dutch roll, probably maintained by the tiny corrections required to land. Apparently, lining up with the runway was tricky in these runs, and poor orientation after the second turn often resulted in a difficult approach.

\section{Landing Using Throttles Only}

This scenario was the same as the previous one (Figure 9), except for the following: The pilot used throttles alone to maneuver, the flaps were set at 65 percent, and there was no yaw rate feedback. He did not use the stick, even though only the rudder was stuck. Landings were attempted with nominal and fast engines, and the pilot was aware of the control mode. The pilot flew conservatively, and was able to line up with the runway without too much difficulty in all cases. This difference in ease of lining up from the previous test using the stick is due to the slower, more sluggish behavior with throttles-only maneuvering that eliminated the tendency to over-control. With throttles only, final approach was much harder than initial alignment with the runway because the flight path adjustments had to be finer, and the pilot was careful not to overcompensate or accidentally initiate a large oscillation. He was able to achieve manageable roll and yaw rates (Figure 13 and Figure 14), although they were larger than he would have preferred. The

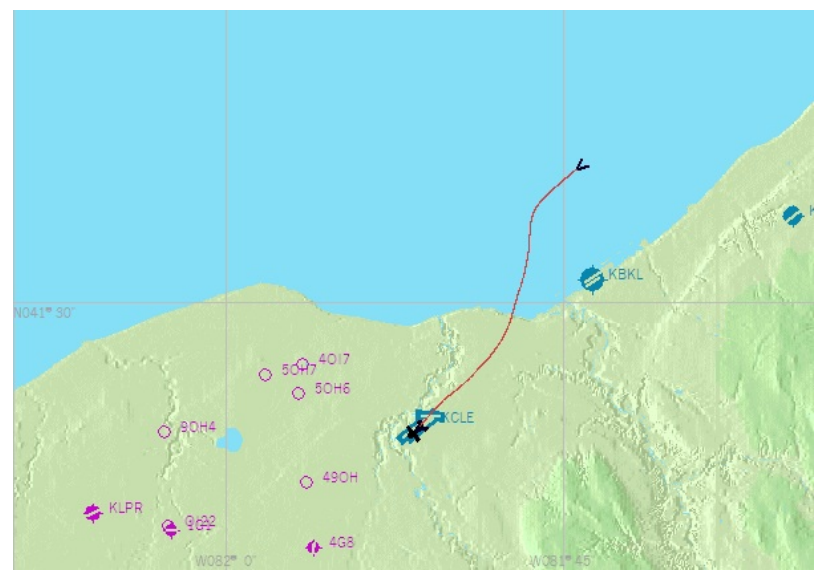

Figure 9.-Ground track of impaired aircraft flying toward airport (CLE).

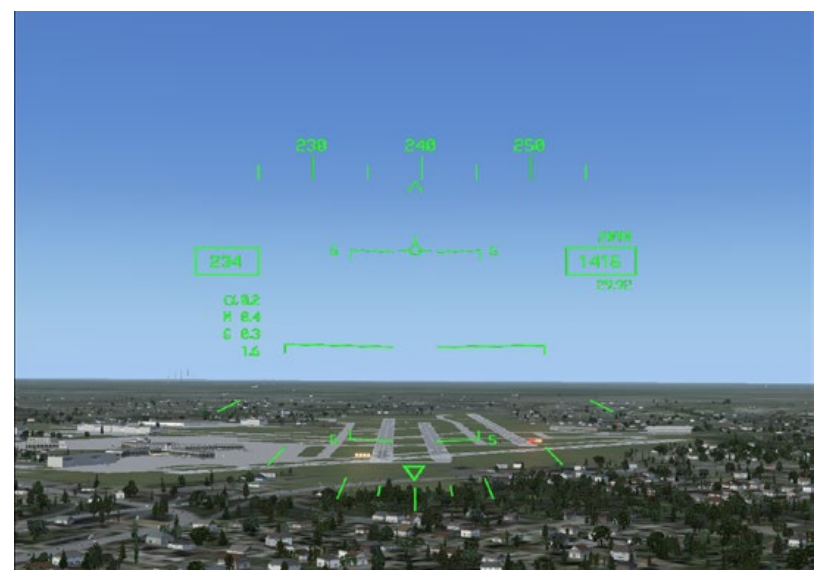

Figure 10.-The pilot's view toward the airport (CLE) on approach. 
pilot felt that the faster engine response provided an advantage for fine tuning. Figure 15 and Figure 16 bear out the pilot's claim. These figures show the time derivative of the throttle movements for similar approaches to emphasize the adjustments the pilot made. Though true for both throttles for the runs shown, for right throttle in particular (Figure 16), it is clear that the pilot made fewer, faster adjustments with the more responsive engines, while he made gentle adjustments more often with the nominal engines. Thus the faster engines provided about the same level of flight control with lower pilot workload. As with the other tests, skill tended to improve with practice.

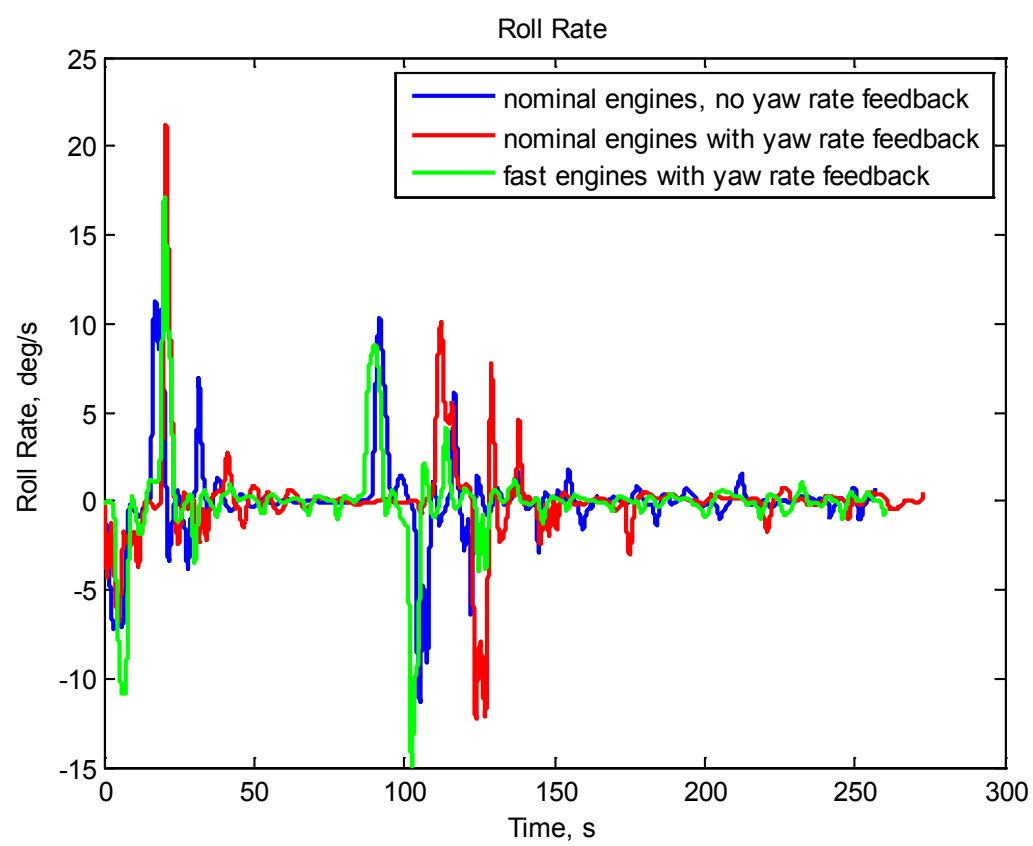

Figure 11.-Roll rate for landing trials using the stick.

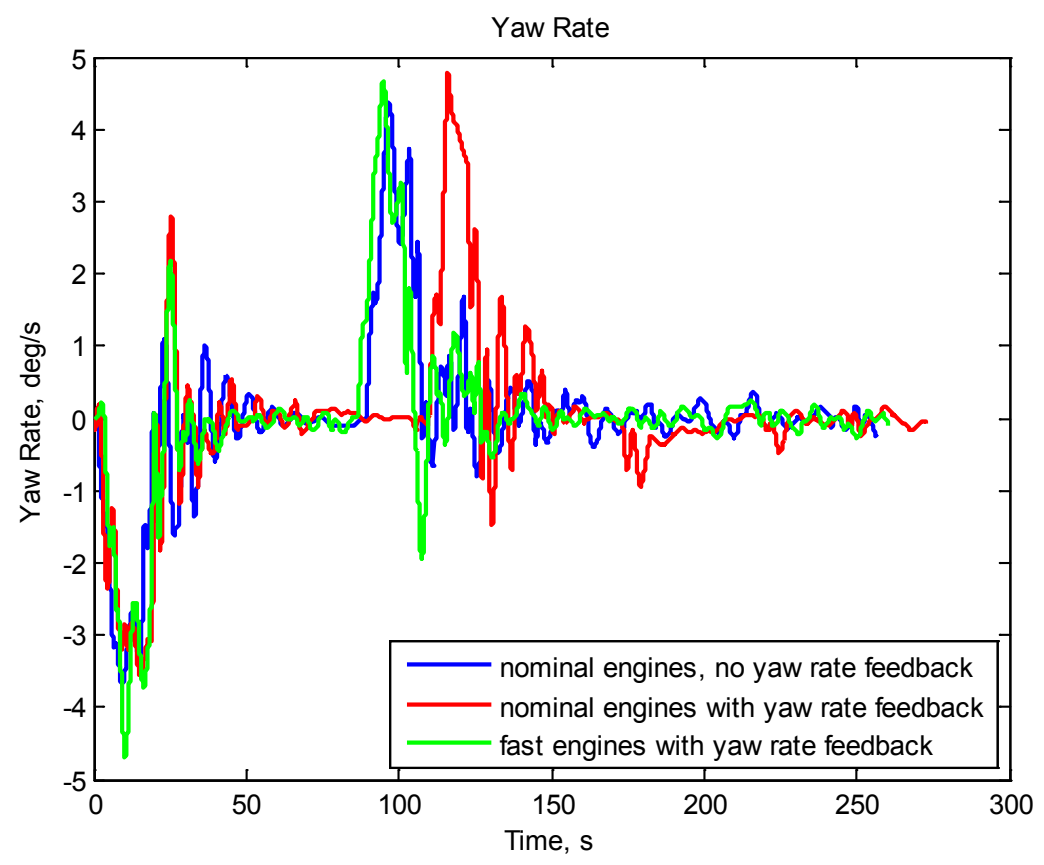

Figure 12.-Yaw rate for landing trials using the stick. 


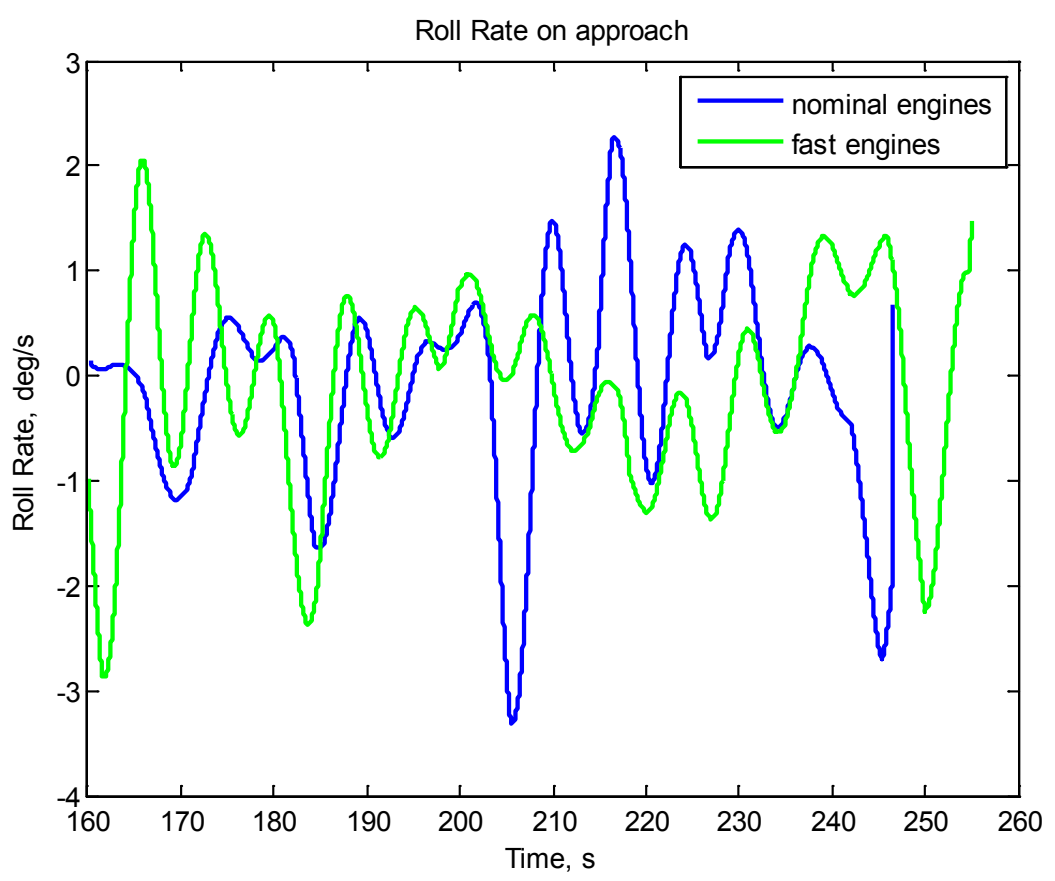

Figure 13.-Roll rate on final approach for throttles-only landing.

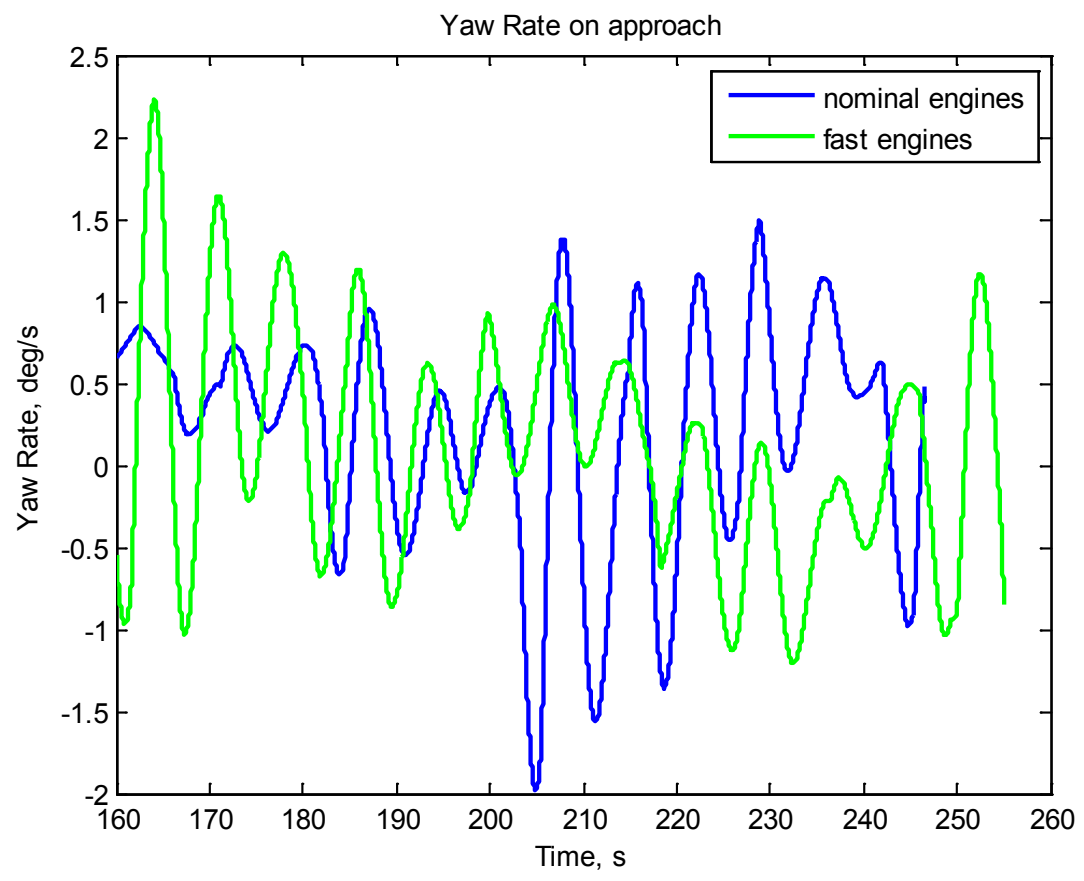

Figure 14.-Yaw rate on final approach for throttles-only landing. 


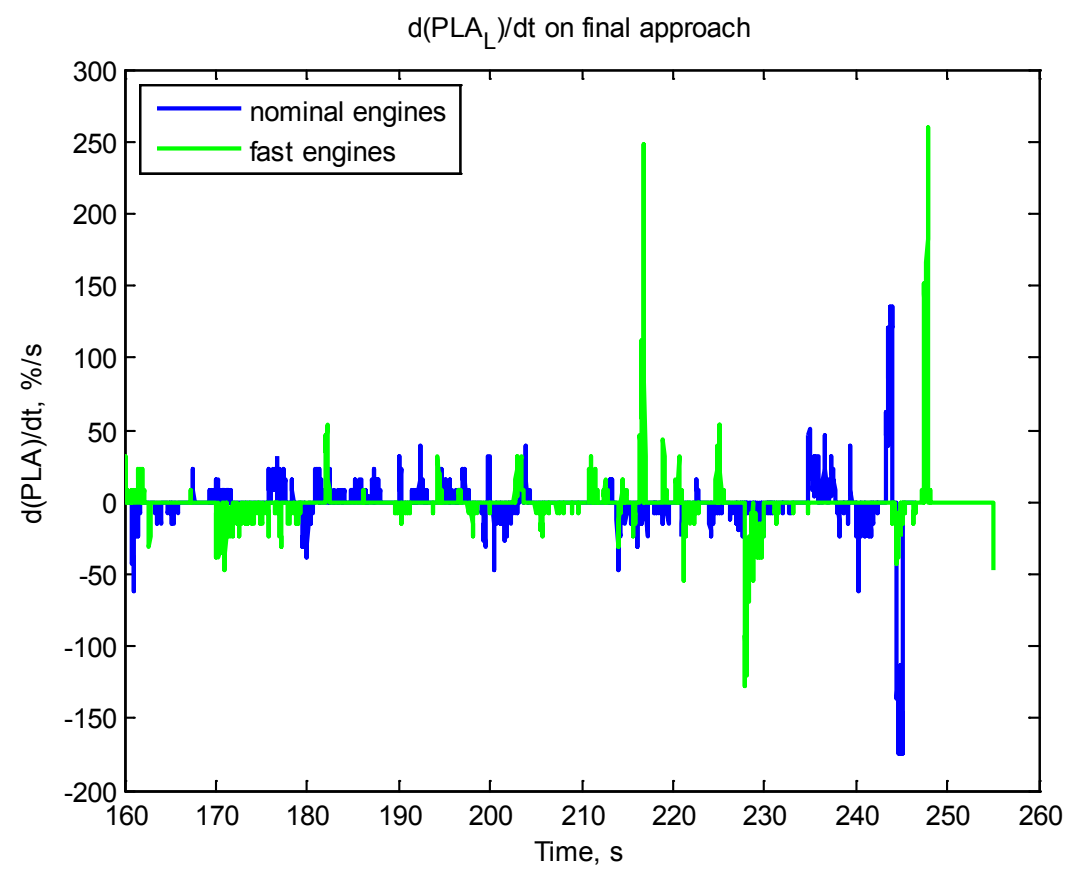

Figure 15.-Time derivative of movement of left PLA on approach for throttles-only landing.

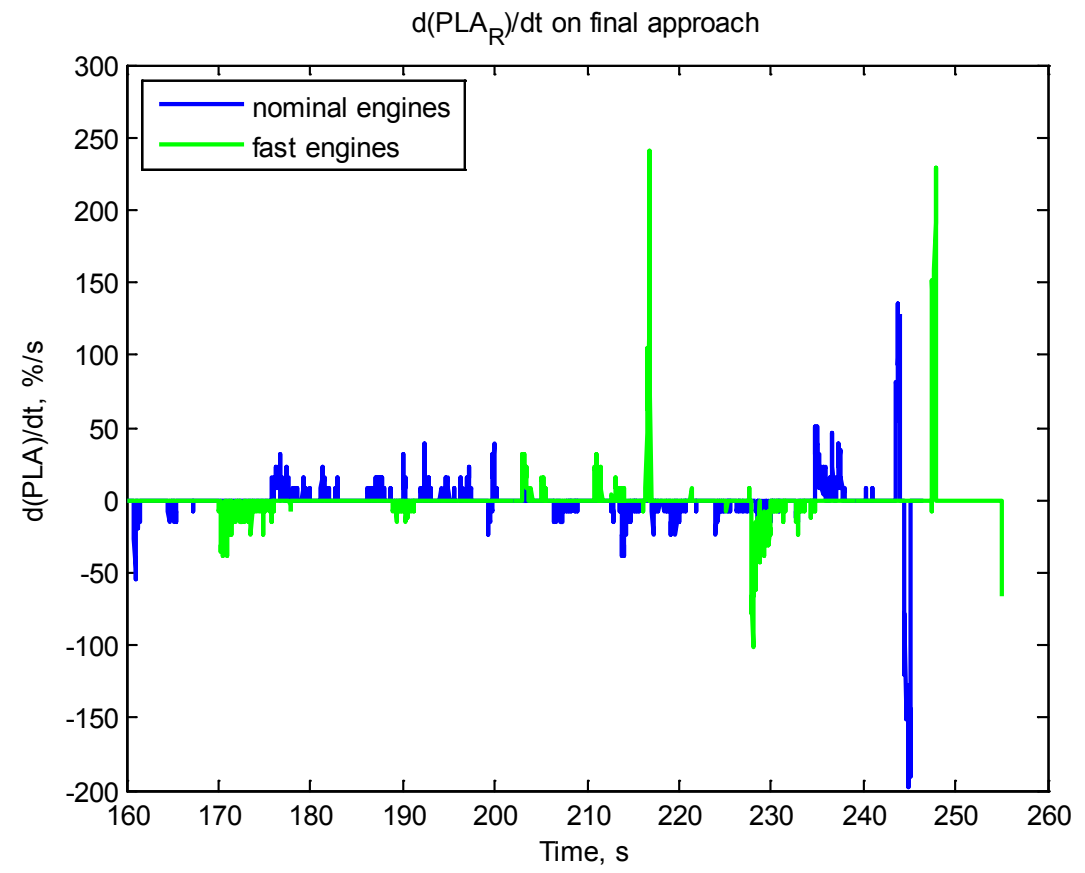

Figure 16.-Time derivative of movement of right PLA on approach for throttles-only landing. It is clear that the pilot made fewer, faster corrections with the faster engines, and smaller adjustments more often with the nominal engines. 
The pilot seemed more comfortable using the throttles for fine tuning than attempting to fly normally with yaw rate feedback to the throttles. This preference was a result of the relatively slow engine response when compared to the rudder; the delay in engine response made small adjustments particularly difficult to accomplish.

The general observations were that there is a clear learning curve in all cases. With practice the pilot was able to land safely more consistently, however, there was greater improvement when using the enhanced control modes. When the pilot had the ability to turn on and off the enhanced control modes, he tended to use Overthrust during flare, which he stated was very useful. Increasing power during flare was used to reduce sink rate. Normally, the stick would be pulled back to settle on the runway, but increasing power caused a similar effect. Therefore, Overthrust capability is considered generally useful for flying, not just for takeoff, when incorporated intelligently or when the pilot knows when to take advantage of it. This is the type of unanticipated benefit exposed by the creativity and resourcefulness of the pilot, and is reminiscent of what happened during the Baghdad event, in which the pilots of the disabled aircraft increased thrust during flare to obtain positive pitch (Ref. 4).

\section{General Impressions}

The pilot had several observations:

- He preferred the throttle to the pedals because he felt he had finer control with the throttles.

- He would have liked to have a sideslip indicator, which is not currently in the simulator's instrumentation. The pilot might have been more willing to use pedals if there had been one available.

- His assumption is that landing on airport grounds is as good as landing on a runway. The ground is hard-packed and relatively obstacle free. In real life, the landing gear may be torn off, but a survivable landing on the aircraft's belly should be possible.

- When landing, it is more important to keep wings level and hit a grassy area than try to maneuver onto a runway. Usually, maneuvering would result in an oscillatory behavior that continued until touchdown, resulting in a crash.

- He tried to have a shallow approach under the glide slope. Steep approaches were harder to control and usually resulted in a crash.

- Throttles-only control needed to be initiated from a stabilized and trimmed condition. Controllability depended on being able to adjust speed to climb or descend.

- If the aircraft is not trimmed, it is very difficult (or impossible) to control the aircraft. Throttles alone cannot easily recover an unstable aircraft.

- The goal was to land on a specific runway, but on approach he tried to minimize changes to flight path, so if another runway was more achievable, it would become the target.

- It is important to watch airspeed during approach. If speed drops off and the aircraft enters into a stall, recovery is not possible because the aircraft is too low. This point is crucial because glide slope is controlled by airspeed.

- Increasing power during flare was used to reduce sink rate. Normally, the stick would be pulled back to settle on the runway. Increasing power caused a similar effect, although more delayed so it requires more anticipation.

- With Fast Response and Overthrust together, landings are easier because the flare is easier to time and to get the necessary power to reduce the sink rate.

- Overthrust was hard to judge and control when used during flight. The difference in the sensitivity to pilot input between when it was on or off was more noticeable than for Fast Response. However, it is good for getting power during climb out, slowing sink rate during landing, and increasing speed when entering into a stall condition. The pilot's difficulty with Overthrust mode during flight was due to its integration into the simulator. The throttle was rescaled for Overthrust to allow for a wider power range over the same range of throttle 
movement. Because of this, the power level changed for a given throttle position with the mode on or off, and moving the throttle a fixed amount resulted in a different change in thrust. This took some getting used to. The implementation is a result of hardware limitations; it is not the desired approach. More instrumentation and more practice would be helpful with this mode in its current implementation.

- There were no unusual dynamics reported as a result of turning the enhanced control modes on and off. The Fast Response mode only impacts engine transients, so its effect is not obvious unless the throttle is moved. Overthrust causes a rescaling of the throttle setting in the current implementation, which can result in a small transient when it is initiated, but since its purpose is to increase the high power setting, its use was most often in conjunction with a desired thrust increase.

- Fast Response had a positive effect on control. Reducing the time lag associated with engine response makes it easier to control the aircraft by alleviating the need to anticipate as much.

- There was trouble flying the simulator due to lack of visual cues and feel. There was no stick shaker to warn of the approach of stall, no ground effect during landing, no sound, and little instrumentation. In general, "sensing" of the aircraft was missing.

- The aircraft was difficult to slow down so the speed needed to be kept low. At lighter weights there was not enough control authority in the throttles to slow it down because power was already reduced. Having a heavier aircraft helped because the throttles had to be set higher, providing more ability to retard them.

- Fast Response has little benefit to improving performance during take-off, although its value is likely to increase the later into the takeoff roll it is initiated. It is most beneficial during throttlesonly flight control.

- Overthrust was most beneficial during take-off and flare. It had limited benefit during throttlesonly flight control.

\section{Conclusions}

On-going piloted flight simulator evaluation of enhanced propulsion control modes was described. The development and testing of these control modes is in response to the shortcomings of throttles-only flight control identified previously by NASA researchers. The engine performance obtained using the enhanced control modes is representative for engines of this thrust class and is considered to be realistically achievable. Overall the piloted test results were very promising. The enhanced control modes showed benefit in multiple scenarios. Although the pilot had some reservations, it is important to realize that the purpose of these evaluations was to characterize situations in which the enhanced control modes would be useful, and ways of implementation that will take advantage of them without being detrimental to handling qualities. In addition to the use of enhanced propulsion control modes here, the testing performed under this effort differs from the previous work with throttles-only control and Propulsion Controlled Aircraft (PCA) in another way. Here only the rudder was failed so other surfaces were functional. The current problem is easier from that point of view, but the yaw rate feedback to the throttles combined with the remaining flight control system resulted in some uncertainty for the pilot that made the final approach difficult. He seemed to prefer no feedback during the fine tuning on approach as long as he was very careful not to excite oscillations. A yaw rate feedback implementation that is better integrated with the rest of the flight control system should improve pilot satisfaction. Additional work should include more tuning of feedback gains around the flight envelope to optimize performance, and evaluation of the resulting system in landing scenarios with crosswind conditions.

All aircraft types and configurations respond differently, and behavior varies around the flight envelope. During this testing it was shown that fast responding engines were clearly better than nominal engines in some cases (e.g., Dutch roll damping at high altitude). It is likely that the benefit would be extended to a wider portion of the flight envelope, particularly landing, for some aircraft. A more intelligent and natural incorporation of these enhanced propulsion control modes is required so that the pilot is not surprised by performance changes. It may not be necessary to go to the extent of developing a 
complete flight control system in the manner of PCA, but handling qualities should not worsen when the enhanced modes are initiated, and any risk accrued by their use should be more than offset by improved overall safety.

\section{References}

1. National Transportation Safety Board, "Aircraft Accident Report, United Airlines Flight 232, McDonnell Douglas DC-10-10, Sioux Gateway Airport, Sioux City, IA, Jul. 19, 1989,” PB90910406, NTSB/AAR-90/06, 1990.

2. National Transportation Safety Board, "Aircraft Accident Report: American Airlines, Inc. McDonnell Douglas DC-10-10, N103AA. Near Windsor, Ontario, Canada, June 12, 1972," PB-219 370, 1973.

3. Faith, N., "Black Box: Why Air Safety Is No Accident," Zenith Press, 1997, pp. 157-158.

4. Lemaignan, B., "Flying with no Flight Controls: Handling Qualities Analyses of the Baghdad Event," AIAA-2005-5907, AIAA Atmospheric Flight Mechanics Conference and Exhibit, San Francisco, CA, Aug. 15-18, 2005.

5. National Transportation Safety Board, "Aircraft Accident Report: Attempted Takeoff From Wrong Runway Comair Flight 5191 Bombardier CL-600-2B19, N431CA Lexington, KY, Aug. 27, 2006," NTSB/AAR-07/05, PB2007-910406, 2007.

6. Job, M., and Swift, S., "JAL123, JAL123 ... uncontrollable," Flight Safety Australia, July-August 2005, Vol. 9, No. 4, pp. 28-33.

7. National Transportation Safety Board, "Runway Collision of USAIR Flight 1493, Boeing 737 and Skywest Flight 5569 Fairchild Metroliner, Los Angeles, CA, Feb. 1, 1991," PB91-910409, NTSB/AAR-91-08, 1991.

8. McGlynn, G. E., Litt, J.S., Lemon, K.A., and Csank, J.T., "A Risk Management Architecture for Emergency Integrated Aircraft Control,” AIAA-2011-1568, Infotech@Aerospace 2011, St. Louis, MO, Mar. 29-31, 2011.

9. Litt, J.S., and Guo, T.-H., "Fast Thrust Response for Improved Flight/Engine Control under Emergency Conditions," AIAA 2008-6503, AIAA Guidance, Navigation and Control Conference and Exhibit, Honolulu, HI, Aug. 18-21, 2008.

10. Burcham, F. W., Jr., Fullerton, C. G., and Maine, T. A., "Manual Manipulation of Engine Throttles for Emergency Flight Control," NASA/TM-2004-212045, Jan. 2004.

11. Tucker, T., "Touchdown: The Development of Propulsion Controlled Aircraft at NASA Dryden," Monographs in Aerospace History \#16, NASA History Office, 1999.

12. Csank, J.T., Chin, J.C., May, R.D., Litt, J.S., and Guo, T.-H., "Implementation of Enhanced Propulsion Control Modes for Emergency Flight Operation,” AIAA-2011-1590, Infotech@Aerospace 2011, St. Louis, MO, Mar. 29-31, 2011.

13. Csank, J.T., May, R.D., Litt, J.S., and Guo, T.-H., "A Sensitivity Study of Commercial Aircraft Engine Response for Emergency Situations," NASA/TM-2011-217004, Apr. 2011.

14. May, R. D., Csank, J. T., Guo, T-H., Litt, J.S., "Improving Engine Responsiveness during Approach through High Speed Idle Control," AIAA 2011-5973, 47th AIAA/ASME/SAE/ASEE Joint Propulsion Conference \& Exhibit, Jul. 31-Aug. 3, 2011, San Diego, CA.

15. Urnes, J.M., and Nielsen, Z.A., "Use of Propulsion Commands to Control Directional Stability of a Damaged Transport Aircraft," AIAA- 2010-3470, Infotech@Aerospace 2010, Atlanta, GA, Apr. 2022, 2010.

16. May, Ryan D., Csank, Jeffrey, Lavelle, T. M., Litt, Jonathan S., and Guo, Ten-Huei, "A High-Fidelity Simulation of a Generic Commercial Aircraft Engine and Controller," AIAA-2010-6630, 46th AIAA/ASME/SAE/ASEE Joint Propulsion Conference and Exhibit, Nashville, TN, July 25-28, 2010.

17. May, R.D., Lemon, K.A., Csank, J.T., Litt, J.S., and Guo, T.-H., "The Effect of Faster Engine Response on the Lateral Directional Control of a Damaged Aircraft," AIAA 2011-6307, AIAA Guidance, Navigation \& Control Conference, Portland, OR, August 8-11, 2011. 



\begin{tabular}{|c|c|c|}
\hline \multicolumn{2}{|c|}{ REPORT DOCUMENTATION PAGE } & $\begin{array}{l}\text { Form Approved } \\
\text { OMB No. 0704-0188 }\end{array}$ \\
\hline \multicolumn{3}{|c|}{ 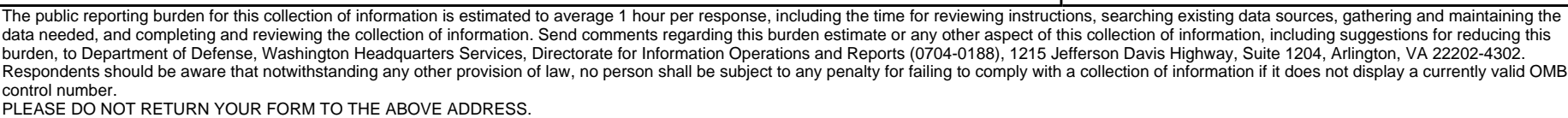 } \\
\hline $\begin{array}{l}\text { 1. REPORT DATE (DD-MM-YYYY) } \\
01-09-2012\end{array}$ & $\begin{array}{l}\text { 2. REPORT TYPE } \\
\text { Technical Memorandum }\end{array}$ & 3. DATES COVERED (From - To) \\
\hline \multirow{3}{*}{\multicolumn{2}{|c|}{$\begin{array}{l}\text { 4. TITLE AND SUBTITLE } \\
\text { Flight Simulator Evaluation of Enhanced Propulsion Control Modes for Emergency } \\
\text { Operation }\end{array}$}} & 5a. CONTRACT NUMBER \\
\hline & & 5b. GRANT NUMBER \\
\hline & & 5c. PROGRAM ELEMENT NUMBER \\
\hline \multirow{3}{*}{\multicolumn{2}{|c|}{$\begin{array}{l}\text { 6. AUTHOR(S) } \\
\text { Litt, Jonathan, S.; Sowers, T., Shane; Owen, A., Karl; Fulton, Christopher, E.; Chicatelli, } \\
\text { Amy, K. }\end{array}$}} & 5d. PROJECT NUMBER \\
\hline & & 5e. TASK NUMBER \\
\hline & & $\begin{array}{l}\text { 5f. WORK UNIT NUMBER } \\
\text { WBS 284848.02.05.03.02.03 }\end{array}$ \\
\hline \multicolumn{2}{|c|}{$\begin{array}{l}\text { 7. PERFORMING ORGANIZATION NAME(S) AND ADDRESS(ES) } \\
\text { National Aeronautics and Space Administration } \\
\text { John H. Glenn Research Center at Lewis Field } \\
\text { Cleveland, Ohio 44135-3191 }\end{array}$} & $\begin{array}{l}\text { 8. PERFORMING ORGANIZATION } \\
\text { REPORT NUMBER } \\
\text { E-18385 }\end{array}$ \\
\hline \multirow{2}{*}{\multicolumn{2}{|c|}{$\begin{array}{l}\text { 9. SPONSORING/MONITORING AGENCY NAME(S) AND ADDRESS(ES) } \\
\text { National Aeronautics and Space Administration } \\
\text { Washington, DC 20546-0001 }\end{array}$}} & $\begin{array}{l}\text { 10. SPONSORING/MONITOR'S } \\
\text { ACRONYM(S) } \\
\text { NASA }\end{array}$ \\
\hline & & $\begin{array}{l}\text { 11. SPONSORING/MONITORING } \\
\text { REPORT NUMBER } \\
\text { NASA/TM-2012-217698 }\end{array}$ \\
\hline \multicolumn{3}{|c|}{$\begin{array}{l}\text { 12. DISTRIBUTIONIAVAILABILITY STATEMENT } \\
\text { Unclassified-Unlimited } \\
\text { Subject Categories: } 07,08 \text {, and } 63 \\
\text { Available electronically at http://Www.sti.nasa.gov } \\
\text { This publication is available from the NASA Center for AeroSpace Information, 443-757-5802 }\end{array}$} \\
\hline
\end{tabular}

\section{SUPPLEMENTARY NOTES}

\section{ABSTRACT}

This paper describes piloted evaluation of enhanced propulsion control modes for emergency operation of aircraft. Fast Response and Overthrust modes were implemented to assess their ability to help avoid or mitigate potentially catastrophic situations, both on the ground and in flight. Tests were conducted to determine the reduction in takeoff distance achievable using the Overthrust mode. Also, improvements in Dutch roll damping, enabled by using yaw rate feedback to the engines to replace the function of a stuck rudder, were investigated. Finally, pilot workload and ability to handle the impaired aircraft on approach and landing were studied. The results showed that improvement in all aspects is possible with these enhanced propulsion control modes, but the way in which they are initiated and incorporated is important for pilot comfort and perceived benefit.

\section{SUBJECT TERMS}

Flight simulation; Propulsion control

\begin{tabular}{|l|l|l|l|c|l|}
\hline \multicolumn{2}{|l|}{ 16. SECURITY CLASSIFICATION OF: } & $\begin{array}{l}\text { 17. LIMITATION OF } \\
\text { ABSTRACT }\end{array}$ & $\begin{array}{l}\text { 18. NUMBER } \\
\text { OF } \\
\text { PAGES }\end{array}$ & $\begin{array}{l}\text { 19a. NAME OF RESPONSIBLE PERSON } \\
\text { STI Help Desk (email:help@sti.nasa.gov) }\end{array}$ \\
\cline { 1 - 2 } $\begin{array}{l}\text { a. REPORT } \\
\text { U }\end{array}$ & $\begin{array}{l}\text { b. ABSTRACT } \\
\text { U }\end{array}$ & $\begin{array}{l}\text { C. THIS } \\
\text { PAGE } \\
\text { U }\end{array}$ & UU & 22 & $\begin{array}{l}\text { 19b. TELEPHONE NUMBER (include area code) } \\
\text { 4t43-757-5802 }\end{array}$ \\
\hline
\end{tabular}



